\title{
Water Retention Curve and Particle Breakage of Aggregates Recycled from Demolition Waste
}

\author{
Alejandra María Gómez Jiménez ${ }^{1}$, Márcio Muniz de Farias ${ }^{1}$, Manoel Porfírio Cordão Neto ${ }^{1}$ and Iván Fernando \\ Otálvaro Calle ${ }^{2}$ \\ 1. Department of Civil and Environmental Engineering, University of Brasilia, Brasilia CEP 70.910-900, Brazil \\ 2. Department of Civil and Industrial Engineering, Pontifical Xaverian University, Cali 118-250, Colombia
}

\begin{abstract}
CDW (construction and demolition wastes) present a high amount of aggregate chips covered with mortar. This results in high absorption of water with a direct impact in particle breakage or disaggregation. It is supposed that intra particle suction plays an important role in this phenomenon. However, WRCs (water retention curves) of CDW are not well understood. In this work, the WRCs of dynamically compacted specimens of aggregates recycled from the demolition of the National Stadium in Brasilia are studied. The objective of this study is to obtain WRCs of the recycled materials by using the pressure plate and filter paper methods. The breaking effect during compaction is quantified from the grain size distribution curves. The particle breakage during compaction increases when the energy is augmented. The results from the WRCs were incorporated into a pore size capillary model to predict pore size distribution.
\end{abstract}

Key words: Construction and demolition wastes, water retention curve, particle breakage.

\section{Introduction}

The amount of CDW (construction and demolition waste) generated in global and local levels is significant. The volume of these materials is increasing with the construction of new buildings and the demolition of old structures that have reached their project life, or due to natural hazards such as earthquakes, storms, floods and anthropic disasters like wars.

Around 300 million $\mathrm{t} / \mathrm{y}$ of $\mathrm{CDW}$ are generated in Europe, about 170 million $\mathrm{t} / \mathrm{y}$ in the United States and 68 million t/y are produced in Brazil. The Federal District (Brasilia) has a daily production of $6,000 \mathrm{t}$, equivalent to an annual production of 2.2 million $t / y$ [1].

Innovation and development of wastes recycling technology try to make these materials suitable for reuse. Applications of CDW, RCA (recycled concrete

Corresponding author: Márcio Muniz de Farias, Ph.D., research fields: pavements and numerical analyses. E-mail: mmuniz94@gmail.com. aggregates) and RAP (reclaimed asphalt pavement) in civil engineering works and infrastructure are now common practice in many countries [2]. Several researches show that $\mathrm{CDW}$ is an attractive alternative material for bases and sub-bases of highway pavements due to its high resistance and its non-expansive behavior [1, 3-5].

Engineering properties like volumetric compressibility, hydraulic conductivity and shear strength are significantly controlled by suction. However, the unsaturated characteristics of CDW materials have not been fully investigated yet. The purpose of this paper is to obtain the water retention and PSD (pore size density) curves of the recycled materials and evaluate its influence on the breakage of particles during compaction. Some conclusions and recommendations are presented.

\section{Water Retention Curve}

The WRC (water retention curve) can be defined as the relationship between the amount of water in a porous material and its matrix suction $\left(s=u_{a}-u_{w}\right)$, 
where, $u_{a}$ is the pressure in the air phase and $u_{w}$ is the pressure in the water phase of an unsaturated soil. The amount of water can be expressed in terms of volumetric water content $(\theta)$, gravimetric water content $(w)$, degree of saturation $(\mathrm{Sr})$, or water index $\left(e_{w}\right)$. The suction is generally plotted in a log scale or in terms potential of suction expressed as a column of water $(p F)$. The ordinate and abscissa axes are interchangeable.

Water retention curves are directly related to PSD curves and they affect important engineering properties, such as volumetric compressibility, shear strength and permeability of unsaturated media [6-9].

The shape of the WRC depends on the pore size distribution and on the compressibility of the porous material with respect to suction [10]. Fig. 1 shows an idealized relationship between the pore-size distribution and the WRC. Each pore-size is associated with a suction value due to the capillarity. A material with a uniform single pore size would present a sharp drop in the water content-suction curve corresponding to the air entry suction. Materials with bilinear pore size distribution would present two such drops. In a material with multiple pore sizes, the
WRC has an "S" shape and presents a more gradual reduction in water content as suction increases. For each dominant pore size, the WRC shows a sharp change in inclination.

Several laboratory techniques are available for determining water retention curves of natural and compacted materials. The pressure plate and the filter paper methods are two low cost alternatives. Low values of suction can be directly applied by means of a hanging column of water in a thin capillary tube. However, this is limited due to cavitation as suction approaches $100 \mathrm{kPa}$. To avoid cavitation, the ATT (axis translation technique) is used in the pressure plate apparatus. The ATT consists in increasing artificially the atmospheric pressure in a porous material sample [11]. The matric suction can be controlled, regulating the air pressure in a test cell, as well as the pressure in water using a saturated porous filter in contact with the sample. Because the base element allows drainage, the amount water that flows through the sample can be quantified and under constant pressures, the flow of water ceases when equilibrium is reached. The WRC is constructed by relating suction and the volume of stored water when the drainage ceases.

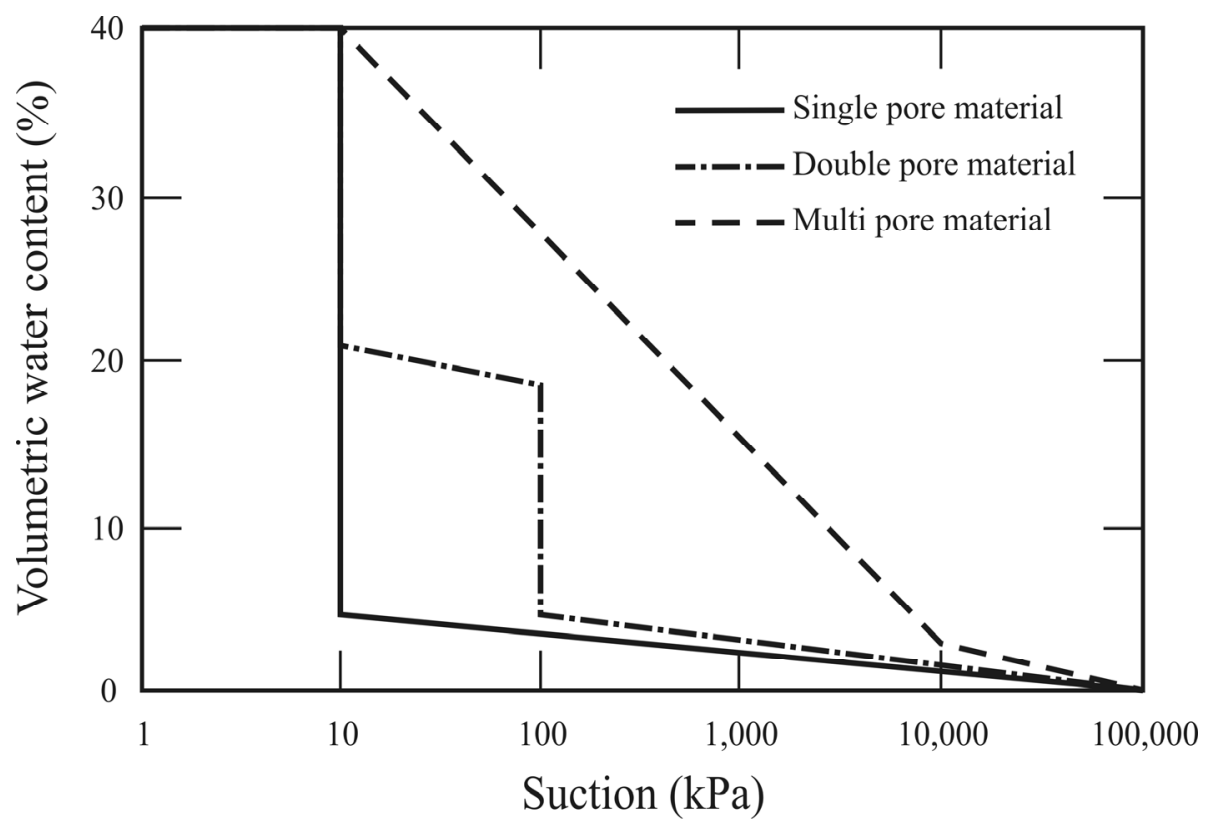

Fig. 1 General shape of water retention curve according to pore size distribution [10]. 
The FPM (filter paper method) has been used since 1937 when it was presented by Gardner. Since then, many researchers have used filter papers for suction measurements [12]. This method is based on the principle that when a wet soil is placed in contact with a drier filter paper inside a sealed container, the paper absorbs water from the soil until both materials reach equilibrium of suction. When the filter paper is in intimate contact with the soil water, the water absorbed by the filter paper has the same concentration as in the soil. In this way, the matric suction is measured. The equilibrium suction is estimated from the measured water content of the filter paper using its calibration curve.

\section{Materials}

A typical construction and demolition waste is a mixture of reinforced concrete blocks, mortar, steel, plastic and wood. The recycled material investigated in this research was collected from wastes of the National Soccer Stadium of Brasilia, which was imploded to give rise to a brand new stadium for the 2014 World Cup in Brazil. For this study, a representative sample of about $1.6 \mathrm{t}$ of $\mathrm{CDW}$ aggregate was used for the laboratory evaluation. Two grinding processes were necessary to obtain the CDW aggregate with the desired grain size distribution required for this investigation.

\subsection{Composition of the CDW Used}

In order to determine the composition of the CDW used in this study, the coarse aggregate fraction retained in the $4.75 \mathrm{~mm}$ sieve was examined visually and segregated manually. The CDW aggregate was separated into four main groups: (1) cementitious materials (the major component of the CDW aggregate, comprised mainly of concrete and mortar, 41\%); (2) crushed rock chips (about 15\%); (3) red ceramics (bricks and roof tiles, 1\%); (4) white ceramics (floor and wall tiles, 1\%). The fine aggregate fraction represented $42 \%$ of the total sample.
Undesirable materials such as metals, wood and plastic represented only a very small proportion of $0.6 \%$, far below the limit value of $3 \%$ imposed by Brazilian standards.

\subsection{Physical Characterization of the Used CDW}

The physical properties of CDW used in this research were determined using Brazilian (NBR) and American standards (ASTM). Tests like water absorption, grain shape, grain-size distribution, sand equivalent, soundness and Atterberg limits were used to determine the physical properties of the recycled aggregate and to define whether it was suitable as base material for highways. The results are summarized in Table 1. Attention is drawn to the water absorption value of $7 \%$, which is due to the presence of ceramics and mortar. This value is high when compared to natural rock chips, but it is not uncommon in CDW which can reach absorption values as high as $15 \%$.

\section{Methodology of Testing and Analyses}

\subsection{Compaction of $C D W$}

Proctor method was used for the compaction of CDW specimens. Modified and intermediate Proctor energy $\left(1,263 \mathrm{kN}-\mathrm{m} / \mathrm{m}^{3}\right)$ were used. The laboratory compaction tests were carried out based on the American Standard procedure (ASTM D1557-07).

Table 1 Summary of physical characteristics of CDW aggregate.

\begin{tabular}{ll}
\hline Properties & CDW investigated \\
\hline Uniformity coefficient $(\mathrm{Cu})$ & 61 \\
Passing sieve \#40, $4.75 \mathrm{~mm}(\%)$ & 15 \\
Passing sieve \#200, 0.075 mm (\%) & $3 \%$ coarse aggregate \\
& $12 \%$ fine aggregate \\
Swelling & $0.0 \%$ \\
Liquid limit & $32 \%$ \\
Plasticity index & $\mathrm{NP}$ (non plastic) \\
Sand equivalent & $70 \%$ \\
Absorption & $7 \%$ \\
Soundness in magnesium sulfate & $6 \%$ coarse aggregate \\
Los angeles abrasion & $11 \%$ fine aggregate \\
\hline
\end{tabular}


The observed values of optimum water content and maximum dry density were $13.0 \%$ and $16.5 \mathrm{kN} / \mathrm{m}^{3}$, respectively, for the intermediate Proctor energy.

The initial grain size distribution curve used for the investigation was close to the upper limit of a gradation envelope, known as "band C", prescribed in the standards of the Brazilian DNIT (National Department for Transport Infrastructure) 141/10-ES. This envelope is commonly used for base and sub-base materials in highways with medium to heavy traffic volume. The upper limit of this envelope was chosen because the material was expected to crush under compaction [1]. Table 2 presents some properties of the specimens used in this research.

\subsection{Evaluation of CDW Particle Breakage}

The most important engineering properties of granular materials such as stiffness moduli, shear strength, volumetric compressibility, consolidation coefficient, and permeability depend on the integrity of the particles or the amount of particle crushing that occurs due to changes in stress. Therefore, it is important to be able to identify and quantify the effects of particle crushing on these engineering properties [13].

In order to evaluate the breaking process due to compaction in CDW aggregates, the grain-size distribution curves before and after the compaction process were compared and Marsal's factor $\left(B_{g}\right)$ was calculated to quantify this breakage. Marsal and Resendiz [14] developed a measure of particle breakage in connection with the design and construction of earth and rockfill dams. While performing large-scale triaxial compression tests, they noticed significant amount of particle breakage. The method computes the changes in individual particle sizes between the initial and final grain size distributions. The difference in the percentage retained is computed for each sieve size. This difference may be positive or negative. Marsal's breakage factor $\left(B_{g}\right)$ is the sum of the differences having the same sign:

$$
B_{g}=\sum_{k} \Delta W_{k}=\sum_{k}\left(W_{k}^{i}-W_{k}^{f}\right)
$$

where, $W_{k}^{i}$ and $W_{k}^{f}$ are the initial (before compaction) and final (after compaction) percentages in weight retained in sieve " $k$ ". Only positive differences are considered in the summation. The lower limit o Marsal's index is $0 \%$ and the theoretical maximum is $100 \%$.

Table 2 Properties of the CDW specimens.

\begin{tabular}{llll}
\hline Property & I & II & III \\
\hline Water content, $w(\%)$ & 9 & 13 & 17 \\
Dry unit weight, $\gamma_{d}\left(\mathrm{kN} / \mathrm{m}^{3}\right)$ & 16.42 & 16.50 & 16.65 \\
Initial void ratio, $e_{0}$ & 0.625 & 0.613 & 0.603 \\
\hline
\end{tabular}

\subsection{Testing Details for the WRC}

CDW aggregate specimens for determination of the WRC were compacted using intermediate Proctor energy and different water content (9\%, 13\% and 17\%). The samples obtained were $100 \mathrm{~mm}$ in diameter and 35 $\mathrm{mm}$ in height and the original grain size distribution fitted the upper limit of envelope C, shown in Fig. 2. The water retention tests were performed using a pressure plate apparatus and the filter paper method.

The pressure plate is shown in Fig. 3 and consists of four main parts: (1) an aluminum cell where a relatively permeable porous disk with high air-entry value $(300 \mathrm{kPa})$ is sealed to the base; (2) a $50 \mathrm{~mL}$ glass burette for measuring the volume of water extracted from the soil sample by the applied suction; (3) an air pressure regulation system with Fairchild precision regulator model $10 \mathrm{~N}$ for applying intermediate suctions between $3 \mathrm{kPa}$ and $200 \mathrm{kPa}$ and a pressure gauge; (4) a hanging column for applying low suctions in the range of $1 \mathrm{kPa}$ to $5 \mathrm{kPa}$.

The testing method was based on the American standard procedure ASTM D6836-02. The ceramic porous stone was previously immersed in deaired water during a period of $16 \mathrm{~h}$. After the immersion process, the saturation of the ceramic stone was checked by a simple permeability test under constant water head. 


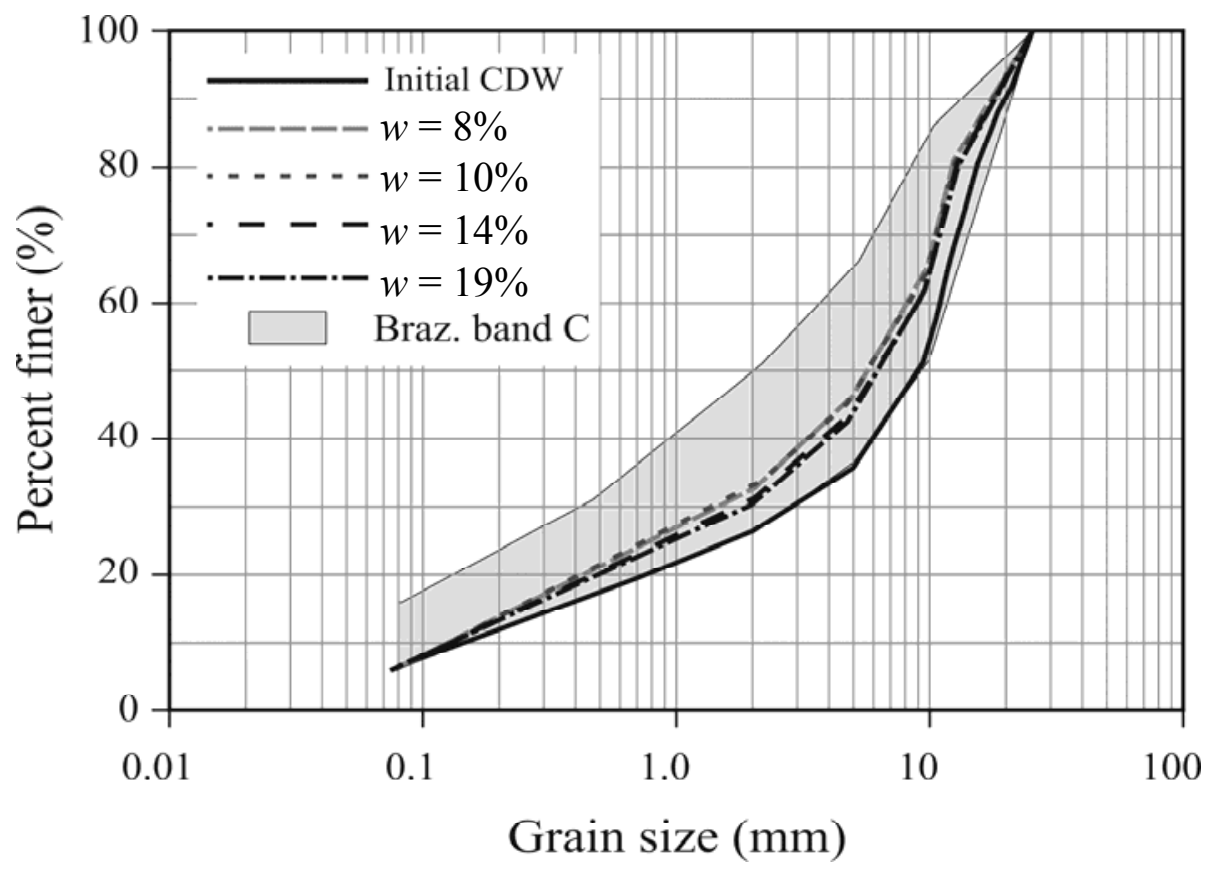

Fig. 2 Grain-size distribution of the recycled material and effect of compaction water content.

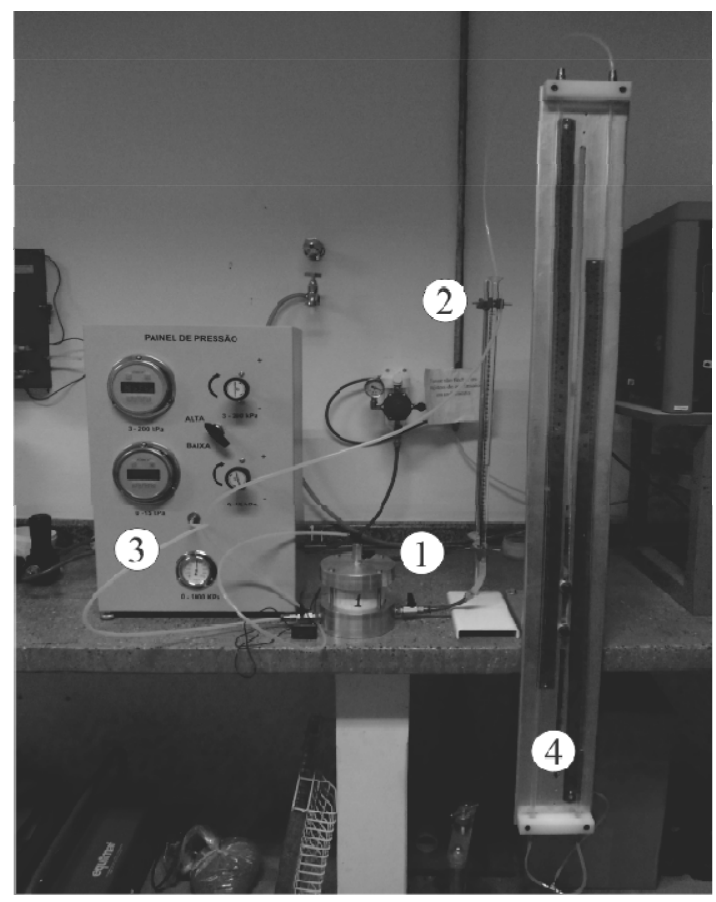

(1) Aluminium cell pressure

(2) Burette

(3) Pressure panel

(4) Hanging column

Fig. 3 Pressure plate with ceramic porous stone coupled with hanging column.

After compaction, the samples were saturated by capillarity. The specimens were placed on a porous stone, covered with a filter paper disk, and placed in a container filled with deaired water up to the base of the compaction mold. Then, the samples were weighed and mounted on the pressure plate apparatus.
Lower suctions (i.e., $1-5 \mathrm{kPa}$ ) were applied maintaining the connection valve between the pressure regulator and the hanging column open. Initially the water outlet was closed and the desired air pressure applied. After air pressure stabilization, the water outlet was opened and equilibrium was reached 
(i.e., the water volume of the burette stabilized). Matric suction was applied until equilibrium was observed what could be verified by plotting the water volume of the burette with respect to time in logarithmic scale. The same procedure was applied to the next higher value of matric suction in intervals of $20 \mathrm{kPa}$ up to the maximum pressure allowed by the air capacity of the regulator valves (around $200 \mathrm{kPa}$ ).

Suction values higher than $100 \mathrm{kPa}$ were determined using filter paper technique. This required the compaction of a sample for each point. After compaction, the specimens were saturated and then air-dried in the lab to attain the chosen value of water content.

A sandwich composed by three pieces of filter paper was placed at the base of each sample after reaching the required humidity. Whatman filter paper number 42 were used immediately after removal from the box in dry condition. The filter paper was carefully handled with a stainless steel tweezer to avoid changing its original characteristics. The sample with both filter papers was wrapped with two layers of PVC (polyvinyl chloride) film, and then placed inside a plastic bag and stored in the EPS (expanded polystyrene) box in a temperature controlled room during 14 days when suction equilibrium is expected to be reached. The equilibrium suction was obtained from the Chandler et al. [15] calibration equation

$$
\log _{10}(s)=\left\{\begin{array}{l}
4.842-0.0622 w, \quad \text { if } w<47 \% \\
6.050-2.48 \log (w), \text { if } w \geq 47 \%
\end{array} .\right.
$$

\section{Results and Discussion}

\subsection{Changes in Grain Size Distribution}

The original and after compaction grain size distribution curves for different initial values of water content $(8 \%, 10 \%, 14 \%$ and 19\%) are shown in Fig. 2. It is noted that the after compaction curves moved towards the center of the gradation envelope, the gray zone in Fig. 2, due to particle crushing. Also, less crushing is observed for the higher water contents. This is due to the fact that water absorbs part of the compaction energy.

\subsection{Breaking Effect on $C D W$}

The change of grain sizes was evident from the leftwards shift in the curves in Fig. 2. These curves represent samples with different initial water content. The most significant changes occur for the samples with lower initial water content $(8 \%)$.

Marsal's degradation indices $\left(B_{g}\right)$ were computed for all samples with different compaction energies. Fig. 4 shows lines of equal degradation. It is noted that by increasing the energy of compaction, there is an increased factor of breakage of the grains and the same parameter decreases with increasing moisture content, as indicated by the arrow in Fig. 4.

\subsection{Water Retention Properties}

The water retention curves were obtained primarily by following a drying or desorption process. Fig. 5 shows the curves that describe the change in gravimetric water content in the $\mathrm{CDW}$ with respect to the change in matric suction. It is noted that for suction values below $100 \mathrm{kPa}$, where the desaturation process of the CDW begins, the results of with the filter paper are lower than those obtained by the ATT (axis translation technique).

The discontinuity between the branches of the WRC obtained with the FPM (filter paper method) and the ATT may result from: (1) At high water content values, the filter paper loses repeatability because it stores more water than its own weight and, therefore, it is hard to calibrate; (2) In the ATT, the curvature of the air-water interface will increase because of the compression of the entrapped air cavity and, as a result, the differential pressure between air and water, which is controlled by the meniscus curvature, will increase [11].

Observing the results in Fig. 5, very little change is noted between the WRC of the different materials for the higher suction values at the right end of the curves. Most differences in the water retention capacity of the 


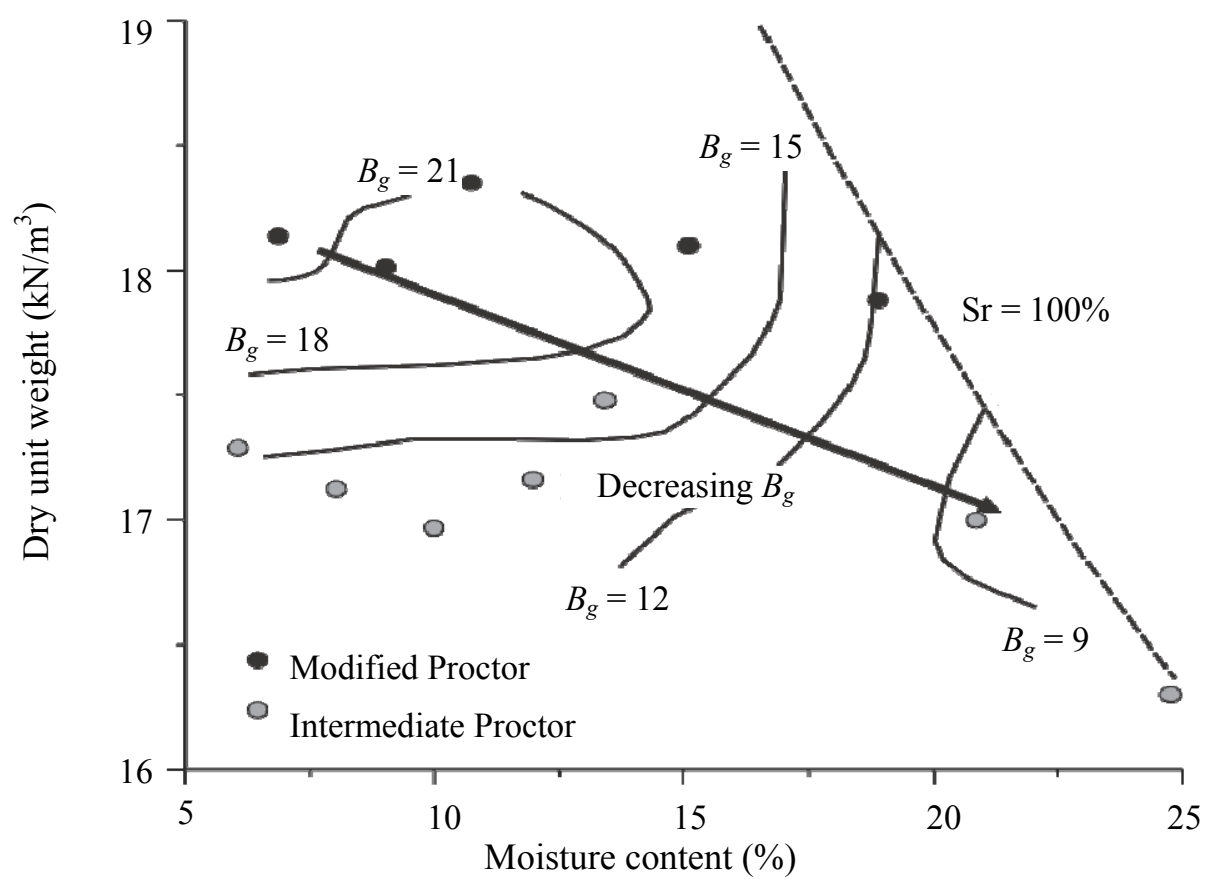

Fig. 4 Lines of equal degradation indices according to sample water content and compaction energy.

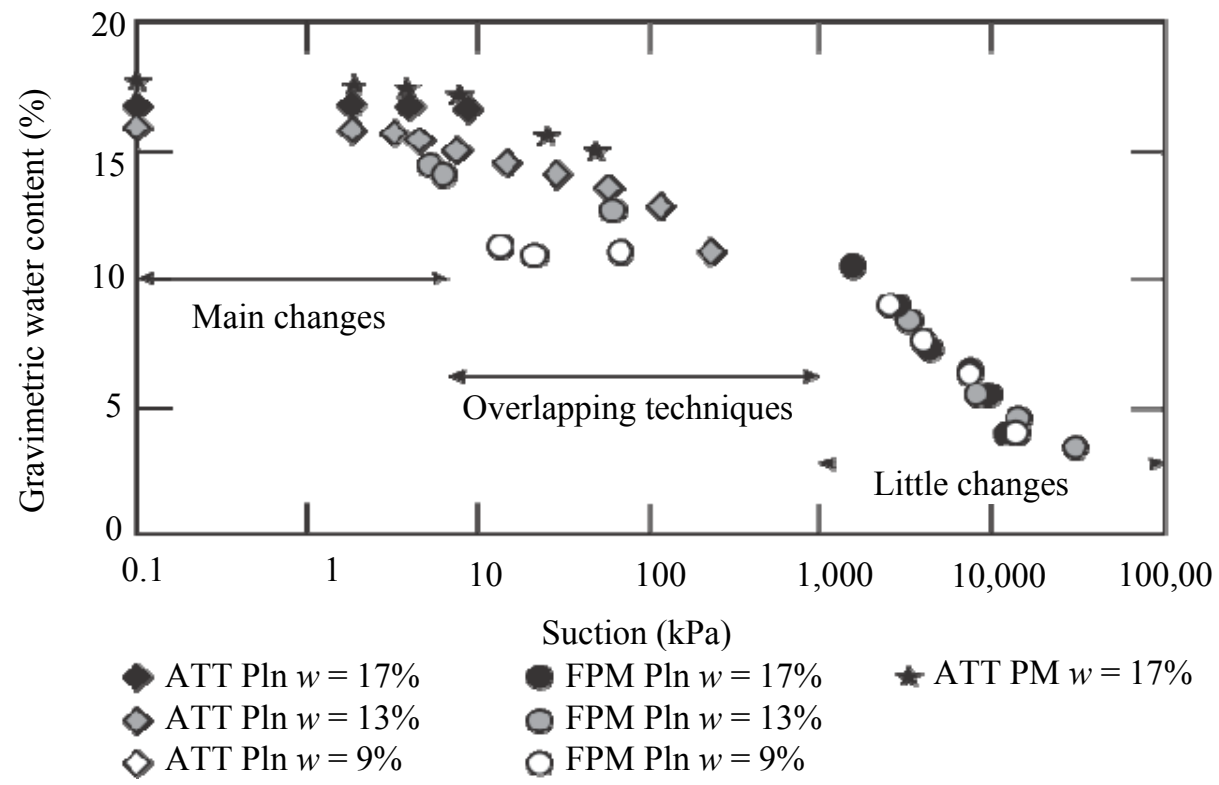

Fig. 5 Water retention curve of CDW.

samples are observed in the initial part of the WRC. These changes in the initial form of the WRC have a connection with the breakage of the particles during the compaction process which is primarily affected by the initial compaction water content and the compaction energy.

The shape of each curve suggests a multi-modal distribution of pores. This is clear for the WRC of the
$\mathrm{CDW}$ at $13 \%$ water content, where it is possible to distinguish at least three dominant pore sizes, from the sharp changes of inclination in the $w-\log (s)$ curve. The larger pores with diameter around $113 \mu \mathrm{m}$ correspond to the voids between the finer sand grains. The intermediate pores with diameter around $1.6 \mu \mathrm{m}$ correspond to voids in the finer silt and clay particles present in the CDW. It is supposed that the smaller 
pores (around $0.03 \mu \mathrm{m}$ ) correspond to voids within the mortar or even within the calcareous aggregate chips used to make the concrete, however, this hypotheses should be checked later using nitrogen absorption technique directly in the aggregate chips.

The dominant pores can be better visualized by plotting the PSD curves. These are obtained from axis transformations on the water retention curves. The ordinates are changed from gravimetric water content $(w)$ to air void indices $\left(e_{a}\right)$ as follows:

$$
e_{a}=e-G_{s} w
$$

where, $e$ is the total void ratio and $G_{s}$ is the specific gravity, on the other hand, the abscissa axis is transformed from capillary suction $(s)$ to pore diameter $(D)$, assuming that in each pore, water and air are separated by a concave interface represented by Laplace equation from which:

$$
D=\frac{4 \sigma}{s}
$$

where, $\sigma$ is the surface tension of the water assumed as $0.072 \mathrm{~N} / \mathrm{m}$ at $20{ }^{\circ} \mathrm{C}$. The transformed $e_{a}-\log (D)$ curve has a shape similar to that of the WRC in Fig. 6, and its slope (first derivative) for each diameter value represents the pore density from which the non-dimensional pore size density curve is constructed as shown in Fig. 7. In the PSD curve,

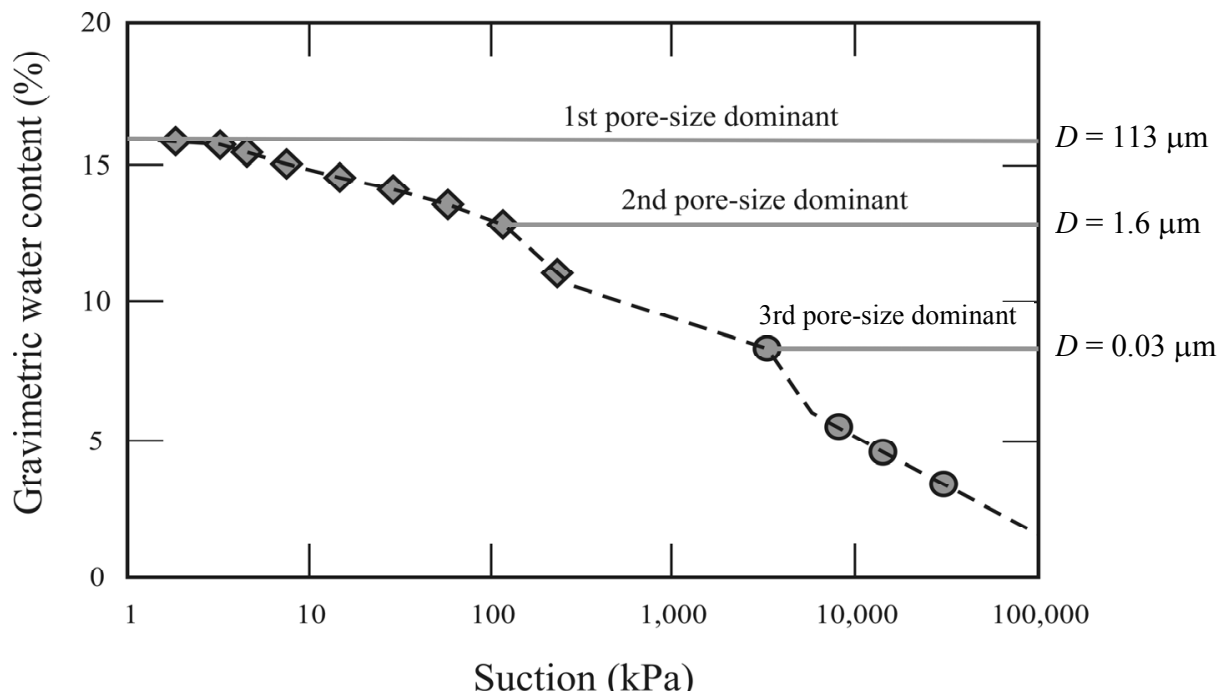

Fig. 6 Multi pore shape in the water retention curve for the compaction water content of $13 \%$. Diamonds refer to points obtained with axis translation and circles with filter paper.

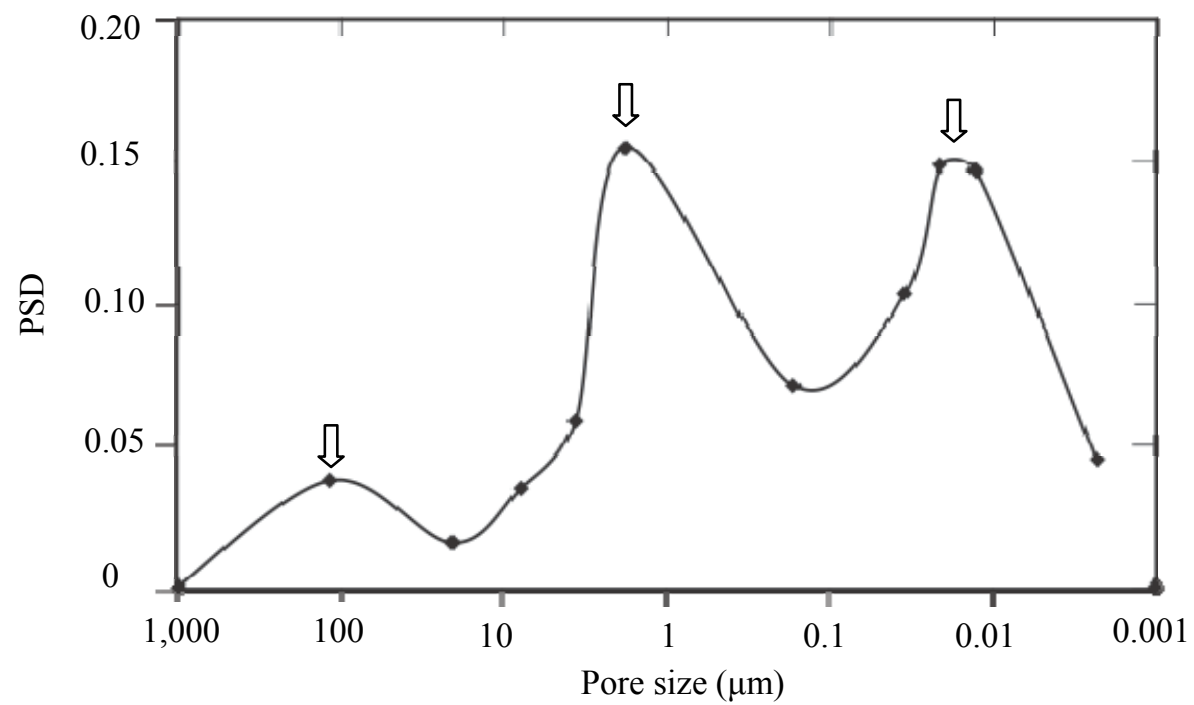

Fig. 7 PSD curve for the compaction water content of $13 \%$. 
dominant pores sizes can be clearly identified as peaks which are indicated by the arrows added to this picture.

Similar curves were obtained for other values of initial water content, but the shapes of the WRCs for low suctions (i.e., $<100 \mathrm{kPa}$ ) were affected by compaction water content. As compaction water content grows, the magnitude of the first air entry value increases. This value is related to the largest pore size. The final part of the curves converges. This occurs for water content values lower than $9 \%$, which is equivalent to the amount of water absorbed by the recycled aggregates studied.

\section{Conclusions}

Particle breakage is a major issue concerning the use of aggregates recycled from CDW. The laboratory results show that particle degradation, as measured by Marsal's index $\left(B_{g}\right)$, is primarily affected by the energy and the initial water content adopted for the compaction process. The reason for the influence of the compaction energy is self-evident, but this investigation shows that the influence of the water content is explained via the matrix suction within the aggregate pores. In order to show this point, it is most important to obtain the water retention curves of the CDW that is not usually found in the literature.

The WRC for specimens of construction and demolition wastes compacted at different water contents and the intermediate Proctor energy were obtained, using a combination of the axis translation technique with the filter paper method. The equipments and techniques used to obtain the WRCs constitute an effective and low cost tool for determining the water retention properties of the construction and demolition waste materials.

The shape of each curve suggests a multi-modal distribution of pores. It is possible to identify three dominant pore sizes using a model that relates the capillary suction with the pore diameters. The dominant pores correspond to voids in the different fractions, such as the coarser aggregates, porous chips and the pores between soils and fine aggregations.

Under the studied laboratory test conditions, it is shown that compaction water content affects the initial part of the WRC, while the end portion remains unchanged. Thus, changes in the initial form of the WRC have a connection with the breakage of the particles during the compaction process.

\section{Acknowledgments}

The authors thank the CNPq (Brazilian National Research Council) and the CAPES (Coordination for the Improvement of Higher Education Personnel) for the financial support for this research.

\section{References}

[1] A.M.J. Gómez, Experimental study of construction and demolition waste for pavement applications, M.Sc. Thesis, Department of Civil and Environmental Engineering, University of Brasilia, Brasilia, 2011, p. 123.

[2] H. Rahardjo, K. Vilayvong, E.C. Leong, Water characteristics curves of recycled materials, Geotechnical Testing Journal 34 (1) (2010) 1-7.

[3] F.D.C. Leite, R.S. Motta, H.L. Vasconcelos, L.L.B. Bernucci, Laboratory evaluation of recycled construction and demolition waste for pavements, Construction and Building Materials 25 (2011) 2972-2979.

[4] C.F. Hendriks, G.M.T. Janssen, Reuse of construction and demolition waste in the Netherlands for road constructions, Heron 46 (2) (2001) 109-117.

[5] T. Park, Application of construction and building debris as base and sub-base materials in rigid pavement, Transportation Engineering, ASCE (American Society of Civil Engineers) 129 (5) (2003) 249-264.

[6] J.R. Nimmo, Porosity and pore size distribution, in: D. Hillel (Ed.), Encyclopedia of Soil in the Environment, Elsevier, London, 2004.

[7] T.M. Thu, H. Rahardjo, E.C. Leong, Elastoplastic model for unsaturated soil with incorporation of the soil-water, Canadian Geotechnical Journal 44 (1) (2007) 67-77.

[8] S.K. Vanapalli, D.G. Fredlund, D.E. Pufahl, Model for the prediction of shear strength with respect to soil suction, Canadian Geotechnical Journal 33 (1996) 379-392.

[9] E. Romero, A. Gens, A. Lloret, Water permeability, water retention and microstructure of unsaturated compacted boom clay, Engineering Geology 54 (1999) 117-127. 
[10] F.A.M. Marinho, Nature of soil-water characteristic curve for plastic soils, Journal Geotechnical and Geoenvironmental Engineering 131 (5) (2005) 654-661.

[11] F.A.M. Marinho, A. Take, A. Tarantino, Tensiometeric and axis translation techniques for suction measurement, Geotechnical and Geoenvironmental Engineering 26 (6) (2008) 615-631.

[12] F.A.M. Marinho, O.M. Oliveira, The filter paper method revisited, Geotechnical Testing Journal 29 (3) (2006) 1-9.
[13] P.V. Lade, J.A. Yamamuro, P.A. Bopp, Significance of particle crushing in granular materials, Journal of Geotechnical Engineering 122 (4) (1996) 309-316.

[14] R.J. Marsal, D. Resendiz, Earth and Earth-Rock Dams, Limusa, Ciudad de Mexico, Mexico, 1975, p. 546.

[15] R.J. Chandler, M.S. Crilly, G. Montgomery-Smith, A low-cost method of assessing clay desiccation for lowrise buildings, in: Proceedings of Institute of Civil Engineering 92 (2) (1992) 82-89. 